\title{
“VIVA O GLORIOSO!” UM ESTUDO SOBRE A FESTA DA IRMANDADE DE SÃO BENEDITO EM ANANINDEUA/PA
}

Sonia Cristina de Albuquerque VIEIRA

\begin{abstract}
RESUMO
O objetivo do artigo será apresentar a festa realizada pela irmandade de São Benedito na região metropolitana de Belém, na cidade de Ananindeua no Estado do Pará, buscando identificar as estratégias de construção de identidade dos devotos do Glorioso Santo Negro, realizada por migrantes vindos da cidade de Bragança, localizada no Nordeste do mesmo Estado. Discutindo todo um processo de perseguição, rejeição e conflitos que desafiam o tempo e guardam heranças herdadas desde a diáspora dos africanos escravizados no Brasil, expressados através do canto, da dança e da resistência negra, até os dias atuais, ainda manifestados nos cortejos e rituais em devoção e homenagem a São Benedito.
\end{abstract}

Palavras-chave: Festa; Irmandade; São Benedito; Ananindeua.

\section{"LONG LIVE THE GLORIOUS!" \\ A STUDY ON THE FEAST OF THE BROTHERHOOD OF SAINT BENEDICT IN ANANINDEUA/PA}

\section{ABSTRACT}

The objective of the article will be present to the festival celebrated by the brotherhood of Saint Benedict held in different cities of state of Pará like Belém, and Ananindeua, In order to identify the strategies of identity construction of the devotes of Glorioso Santo Negro, migrants from the city of Bragança, located in the Northeast of the same State. Discussing a whole process of persecution, rejection and conflicts that provocates the time and keep inheritances inherited from the diaspora of the Africans enslaved in Brazil, expressed through singing, dancing and black resistance, until the present day, still manifested in the comparisons and rituals in devotion and homage to St. Benedict.

Keywords: Party; Brotherhood; St. Benedict; Ananindeua.

\section{UN ESTUDIO SOBRE LA FIESTA DE LA IRMANDAD DE SAN BENITO EN ANA- NINDEUA/PA}

\section{RESUMEN}

El objetivo del artículo será presentar la fiesta realizada por la hermandad de San Benito en la región metropolitana de Belém, en la ciudad de Ananindeua en el Estado de Pará. Buscando identificar las estrategias de construcción de identidad de los devotos del Glorioso Santo Negro, realizada por migrantes venidos de la ciudad de Bragança, ubicada en el Nordeste del mismo Estado. Discutiendo todo un proceso de persecución, rechazo y conflictos que desafian el tiempo y guardan herencias heredadas desde diáspora de los africanos esclavizados en Brasil, expresados a través del canto, de la danza y de la resistencia negra, hasta el día de hoy, aún se manifiesta en las comparaciones y rituales de devoción y homenaje a San Benito.

Palabras clave: Fiesta; hermandad; San Benito; Ananindeua.

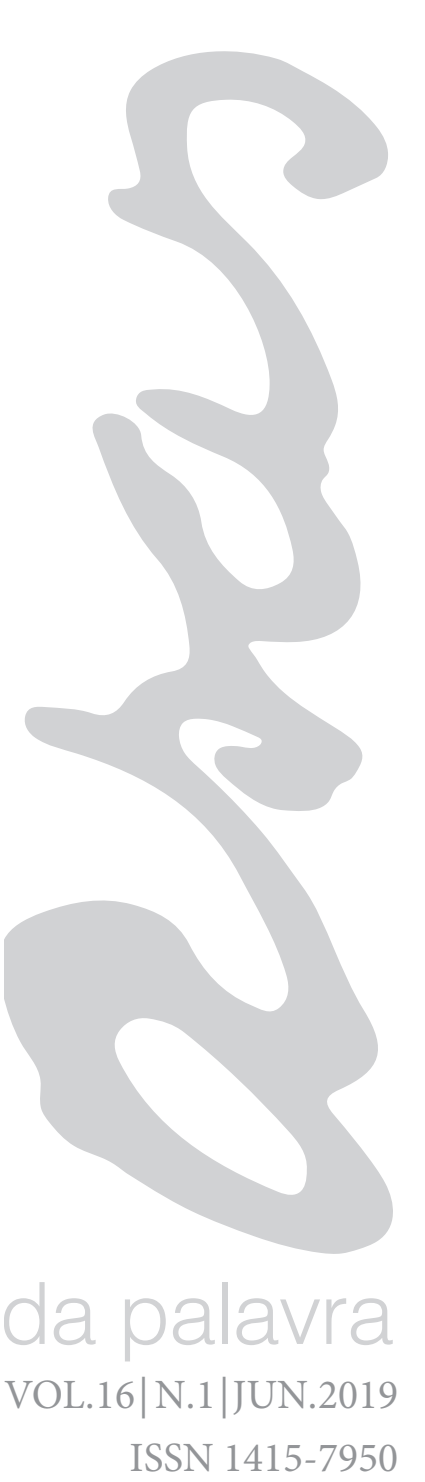




\title{
AS IRMANDADES
}

As irmandades têm origem na Europa Medieval sendo formadas pelos leigos que viviam nos burgos, já que no campo as antigas tradições dos povos eram mantidas; com a ascensão da burguesia, a independência destes leigos foi se tornando cada vez mais presente e desempenhou um papel importante na vida daquele continente, estando ligadas até o século XI as corporações de ofícios.

\begin{abstract}
As Irmandades por juramento podiam ser restabelecidas para o fim da criação de uma relação Associativa Política e da usurpação de poder diante dos senhores das cidades. Mas o movimento podia também partir das corporações de proteção que, em grande número, haviam surgido no Norte e na Inglaterra. (WEBBER, 2009, p. 441).
\end{abstract}

A autonomia das irmandades ou confrarias passou a chamar a atenção dos clérigos, pois devido ao desenvolvimento dos burgos ou cidades, a autonomia dos leigos cresceu a ponto de fragilizar a autoridade dos bispos que até o momento detinham uma boa parcela do acúmulo econômico medieval, com a ascensão das universidades administradas por leigos. Isso despertou a atenção dos epíscopos, abades e principalmente do papado, para com as organizações laicas existentes na Europa medieval, gerando assim um questionamento sobre o que deveria ser feito para em relação à expansão e controle das irmandades. Segundo Vauchez, uma das soluções encontradas foi ligar até então irmandades autônomas as ordens medicantes, já existentes ou a alguma abadia como oblatos:

\begin{abstract}
Mais depois desta data (1280), o papado para controlar melhor esses movimentos, os situou sob jurisdição das ordens medicantes. Em 1286, o mestre geral dos dominicanos Muño de Zamora, criou a terceira ordem dominicana, e, em 1289, o papa Nicolau IV instituiu a ordem terceira franciscana pela bula Supra Montem, que ligava a ordem dos irmãos menores no plano institucional, os penitentes que vivam em suas próprias casas. (VAUCHEZ, 1995, p. 144).
\end{abstract}

Em homenagem a São Benedito e a Nossa Senhora do Rosário foram organizadas no Brasil um grande número de "irmandades" que, segundo Miranda (2006), se tratavam de associações corporativas e dirigidas por leigos que no período da romanização geravam inúmeros conflitos com os párocos. Para ela, as Irmandades negras eram a única forma de inserção social do negro na sociedade colonial e de conciliação entre o modo de pensar africano com os valores do catolicismo branco vigente no período.

As irmandades de africanos se subdividiam de acordo com as etnias de origem, havendo, por exemplo, as de "angolas", "jejes" e "nação". Cada irmandade possuía o seu santo padroeiro, que era homenageado com festas, rezas e ladainhas; para realizá-las, donativos eram recolhidos entre os membros, sendo necessária a cobrança de anuidade e o pagamento de uma taxa para quem quisesse ingressar.

Nos últimos anos, as irmandades negras foram interpretadas sob diversos ângulos que revelam sua complexidade. Um estudo que serve de referência para o tema é o de Caio Boschi, Os leigos no poder. Irmandades leigas e política colonizadora em Minas Gerais (1986). O autor considera as irmandades como um espaço de "domesticação". Já Antônia Quintão, em Lá vem o meu parente. As irmandades de pretos e pardos no Rio de Janeiro e em Pernambuco (século XVIII) - (2002), vê as irmandades como um espaço de resistência e preservação cultural. Outra autora é Célia Maria Borges, a qual em Escravos e libertos nas irmandades do Rosário. Devoção e solidariedade em Minas Gerais- Século XVIII e XIX, (2005), concebe-as como um espaço VOL. 16 | N.1 | JUN. 2019 de ressignificação. 
Mariza Soares, em Os devotos da Cor, Religiosidade e Identidade Étnica no Rio de Janeiro do século (2001) relembra que as irmandades chegaram ao ponto de criar sociedade paralela á sociedade branca da época. João José Reis, em A morte é uma festa. Ritos funerais e revolta popular no Brasil do século XIX (1991) convida o leitor a conhecer o universo da morte na cultura e religiosidade da época. Já Eliana da Silva Miranda, em sua dissertação de mestrado: Negras raízes: Fé, liberdade e resistência na irmandade de São Benedito em meados do século XIX em São Paulo (2006), privilegia o estudo da irmandade no espaço urbano como "territórios negros" durante o século XIX.

Boschi (1986) considera que as irmandades não só possuíam um profundo significado histórico, mas também eram "famílias artificiais" onde as necessidades fora do âmbito familiar eram satisfeitas e uma forma de dominação do branco, pois, através da irmandade o negro assimilava a cultura europeia, incorporava sua personalidade e o levava a passividade conformista. Hoornaert (1978) também vê as irmandades como formas de cooptação de escravos por uma política colonialista através do abuso da religião, mas admite que as confrarias se insurgiram procurando um espaço de liberdade num mundo de dominação, onde a colônia ameaçava tudo que se lhe opunha.

Reis (1991) nos relata a importância das irmandades, principalmente na hora da doença e da morte, assistindo os irmãos que provavelmente teriam seus corpos abandonados à porta de uma igreja, enterrados em vala comum ou abandonados em vias públicas se não fossem por elas. $\mathrm{O}$ autor conclui que as irmandades parecem ter desempenhado um importante papel na formação de uma 'consciência negra', embora consciência dividida, que desabrochou no Brasil com o fim do regime colonial. Reis (1991) ainda coloca que é incontestável o valor que tiveram como instrumentos de resistência, permitindo a construção ou a reformulação de identidades que funcionaram como um anteparo à desagregação de coletividades.

Submetidas a imensas pressões. Mesmo que tenham sido seletivas nas alianças que promoveram, mostraram, em muitos casos, ser possível a convivência na diferença, sem prejuízo da capacidade de resistir. Seu limite maior, evidentemente, foi a própria escravidão, que, entretanto não foi aceita sem críticas.

Soares (2001) mostra que através das irmandades construiu-se uma sociedade negra, na qual o negro pode construir um mundo no qual ele era seu próprio senhor. Já Quintão (2002) apresenta vários relatos de irmandades lutando judicialmente para sua manutenção ou intervindo em injustiças e abusos cometidos contra escravos; segundo a autora, as lutas eram constantes devido ao preconceito sofrido por eles.

Em seu artigo intitulado: Simbolizando a devoção: irmandades, cemitério e enterramentos em Porto Alegre no século XIX, Mauro Dillmann Tavares (2008) analisa as expressões de devoções nas irmandades de Porto Alegre no que diz respeito às possibilidades no trato com os enterramentos a partir da organização do cemitério geral a cargo da Santa Casa de Misericórdia no decorrer da segunda metade do século XIX, onde era grande o esforço das irmandades em busca de enterrar seus mortos.

\section{A FESTA DE SÃO BENEDITO EM ANANINDEUA}

A festa em homenagem a São Benedito em Ananindeua/PA é um ritual realizado por migrantes oriundos da cidade de Bragança ${ }^{1}$, interior deste mesmo estado, onde acontece uma tradicional festa para São Benedito há mais de 200 anos. E durante 30 anos este grupo reproduz esta festa em Ananindeua, cidade pertencente à região metropolitana da capital do estado, Belém, aos moldes da que é realizada em Bragança, celebrando o que
1 Uma das cidades mais antigas do estado do Pará, segundo a publicidade e os pertencentes do local. Mais informações ver: MAUÉS. Origens históricas da cidade de Bragança. In: Separata da Revista de História número: 72. SP, 1967.

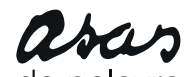

da palavra 
será interpretado como "bragantinidade", ou seja, a presença de elementos simbólicos para representar o pertencimento aos nascidos na cidade de Bragança com determinadas formas de fazê-lo, traduzidas nesta 'condição' de bragantinos. Será assim, em torno da festa, que serão acionados os elementos que marcam esta celebrada identidade.

A cidade de Bragança é o local que dá início ao culto a São Benedito desde 1798. O mito de origem da festa, bastante difundido entre e pelos nativos da região, diz que tudo começou quando os negros escravizados pediram aos seus senhores para erguer uma igreja em homenagem ao santo. Pedido atendido, foi fundada a Irmandade ${ }^{2}$ de São Benedito e como forma de agradecimento eles realizaram uma grande festa. $\mathrm{O}$ gesto se repetiu ano a ano e deu origem à "Marujada de Bragança", manifestação devocional que reúne danças, canções e ritmos específicos em louvor a São Benedito. E que ao longo de duzentos anos vem sendo repetida e atualizada pelos devotos bragantinos a ponto de ganhar o foro de manifestação cultural prestigiada e evidenciada como item privilegiado da identidade dos nativos do lugar, da própria cidade e da região bragantina.

Um dos escritores bragantinos que escreveu sobre a festa de São Benedito da cidade de Bragança foi Armando Bordallo, cuja obra Contribuição ao Estudo do Folclore Amazônico na Zona Bragantina, conclui que a Marujada como se apresenta em Bragança é uma manifestação folclórica tipicamente bragantina por diversas razões segundo o autor; apesar da nomenclatura "marujada", na região bragantina não ocorreu às dramatizações de feitio marítimo, como em outros estados. Outra característica da Marujada é a dança denominada Retumbão ${ }^{3}$. Nonato da Silva, historiador, bragantino e autor da dissertação de mestrado: Os donos de São Benedito: Convenções e rebeldias na luta entre o catolicismo tradicional e devocional na cultura de Bragança, século XX cita o autor Bordallo, ao dizer que a dança da Marujada existe desde o período das navegações em Portugal; ao ser trazida para o Brasil é transformada em uma espécie de bailado popular, possivelmente entre fins do século XVIII e início do século XIX, porém com um caráter mais erudito, por influência de poetas inclusive com um nome Chegança de Marujos. O ponto alto da festa ocorre em dezembro, mas sua preparação no mês de maio 4 , quando se dá início ao período de "esmolação", que tem como propósito levantar fundos para a festa. Na esmolação, três imagens do santo percorrem diferentes áreas da região bragantina e ganham uma denominação própria. O São Benedito "das águas" que segue em romaria fluvial, no dia 8 de dezembro, até o porto de Bragança; São Benedito "das colônias" que percorre as comunidades próximas à Bragança e o São Benedito "dos campos" que se faz presente nas áreas rurais de Bragança. Na esmolação, a "comitiva"

2 Sobre Irmandades Católicas além dos estudos de FIGUEIREDO, já citados, ver também, estudos anteriores GALVÃO, 1955; AZZI, 1977; HOORNAERT, 1974; BOSCHI, 1986; (MAUÉS, 1987 entre outros.

3 ver: Miranda, Nicanor. Marujada. Divisão e Recreio. Departamento de cultura de São Paulo.

$4 \mathrm{Na}$ verdade bem antes, pois para saírem os grupos de esmoladores para cada espaço a que se dirigem, isso exige um preparo e uma organização anteriores.

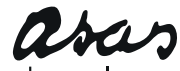

da palavra ISSN 1415-7950 de devotos do santo vai de casa em casa e é recebida com ladainhas e rezas, além de uma oferta de doces e comidas feitas por quem recebe o santo. $\mathrm{O}$ ritual da esmolação só termina no domingo anterior ao início da grande festa, quando as três imagens retornam à cidade e são recebidas, conjuntamente com muita alegria e foguetes pelos moradores. Segundo Silva (1997), autor da dissertação de mestrado: Os tambores da esperança: um estudo sobre a cultura, religião, simbolismo e ritual na festa de São Benedito da cidade de Bragança, a "Marujada de Bragança" é um ritual de louvor com danças e música, onde um grupo de mulheres e homens, denominados marujos e marujas, vestem-se com roupas características nas cores branca e azul em homenagem ao Menino Jesus, nos dias 25 e 31 de dezembro; e de branco e vermelho em homenagem a São Benedito, no dia 26 de dezembro, dia da festa do santo e daí em diante, nos outros dias da festividade, reunindo-se no "barracão" para dançar ao toque de instrumentos específicos e ritmos próprios da festa. A música é tocada por homens, os "tocadores da marujada", que tocam instrumentos que são: tambor, pandeiro, banjo, reco, onça e rabeca. VOL. 16 | N.1 | JUN.2019 Vestidas de capitoa e subcapitoa, duas mulheres comandam a festa, em que, 
divididas em duas filas, outras mulheres, as "marujas" saem dançando e cantando por toda a cidade no auge da festividade: o mês de dezembro. Com túnica de mandrião branco, saia vermelha e azul, colares de contas, fitas coloridas e chapéus de abas douradas, altos confeccionados com penas brancas de patos, as "marujas" dançam em passos ligeiros e curtos ao ritmo do retumbão ${ }^{5}$, tocado pelos homens, os "marujos", que vão atrás delas, nos últimos lugares das filas, tocando ainda seus tambores, pandeiros, cuíca, rabeca, viola, cavaquinho e violino. O autor analisa ainda a festa de São Benedito de Bragança: a Marujada, a utilização das comitivas de Esmoleiros de Bragança trajando opas, que é uma vestimenta utilizada na esmolação de São Benedito pelos rezadores, (esmoladores) promessas. Sendo assim, segundo o referido autor, a mais primitiva e original das manifestações de identidade de culto a São Benedito, por se encaixar na delimitação metodológica dos gestos populares pela busca e alcance de uma resistência ao cativeiro do catolicismo disciplinador e da fuga ao rompante processo que a então prelazia de Nossa Senhora do Rosário do Guamá movia pela reintegração de posse dos bens patrimoniais e culturais da festividade como um todo, contra a ainda "viva" Irmandade de São Benedito de Bragança, a qual consequência, a sua Marujada chegou ao período no século XX intimamente ligada às principais tradições da cidade de Bragança.

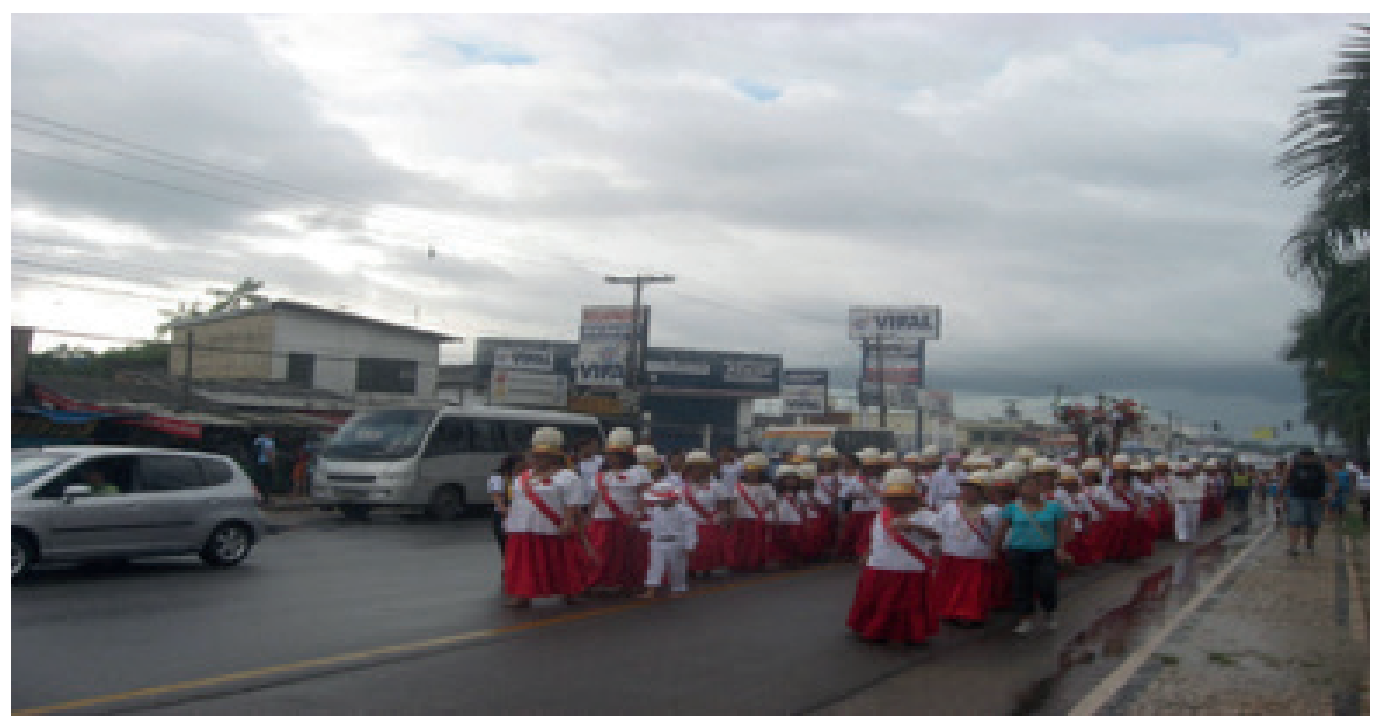

\section{FESTA DO SÃO BENEDITO DE ANANINDEUA} Fig 1: Marujada. Arquivo
Pessoal. Fonte: Sonia Vieira.

A festa em homenagem ao Glorioso São Benedito em Ananindeua iniciou-se com dona Amélia Sulamita Santana dos Santos, natural de Bragança e "descendente de escravos" em 1985. Ela conta que a festa foi o pagamento de uma promessa feita para São Benedito, pois permaneceu cega ao longo de 10 anos de sua vida e, então fez a promessa de realizar uma festa entre os bragantinos de Ananindeua, caso fosse curada. A festa começou a ser realizada em uma antiga "invasão" na cidade de Ananindeua chamada por seus moradores de "Lago azul6" e contou com a participação de cerca de 50 pessoas. Uma das moradoras, Maria Luiza conta que o local, onde a Marujada se apresentava "era todo coberto de plástico" e que os juízes da festa foram sempre sua filha e netos.

A festa ficou sob a responsabilidade de Dona Amélia durante os cinco anos que corresponderam ao tempo do pagamento da promessa até o falecimento de seu marido, quando não teve mais condições para organizar a festa e assim procurou uma pessoa que fosse tão "filho de Bragança" como ela, capaz de continuá-la em seu lugar e perpetuar a tradição entre os

5 O ritmo mais característico da marujada.

6 Nome de um condomínio de luxo da cidade de Ananindeua que também existe desde a década de 60 (PENTEADO,1968), como a "invasão", segundo Maria Luiza, ficara próximo dele, os moradores passaram a chama-la pelo mesmo nome. 
bragantinos de Ananindeua. Inicialmente, Raimundo do Socorro Souza recusa o convite, mas ele relata o seguinte:

Quando minha tia me pediu para assumir a festa eu recusei, achei que era muita responsabilidade; nesse momento eu fui soltar um foguete (para São Benedito) e queimei minha mão ${ }^{7}$; naquele momento o pretinho tava me castigando porque eu tinha recusado, é como se ele me falasse: "Careca, segue o teu destino" e eu não podia fugir, voltei lá com ela e aceitei e tô aqui e vou fazer essa festa enquanto vida eu tiver.

A partir do momento em que Careca assume a presidência, ele dá outro rumo à festa, transferindo-a para o bairro da Cidade Nova VI, onde ele reside, precedida da imagem do santo que segundo ele lhe, foi dada por dona Amélia ${ }^{8}$, imagem que ele tentou "batizar" várias vezes na Igreja do Divino Espírito Santo, localizada na Cidade Nova VIII, e, onde o santo teria permanecido durante 7 dias. Nesta paróquia, o pároco era muito amigo de Marcelo, filho de Merca, que na época também era seminarista; segundo ele, o padre doou um terreno para o Careca construir uma capela para São Benedito, mas devido ao seu falecimento um novo pároco assume a paróquia e o terreno de Careca para construir uma capela dedicada a Nossa Senhora do Perpétuo Socorro, ou seja, São Benedito fica sem um templo religioso, pois é um santo da marginalidade e que sofre "perseguição" segundo os bragantinos pela Igreja oficial.

\section{IDENTIDADE E RESISTÊNCIA}

Fig. 2: Dança da Marujada. Arquivo Pessoal. Fonte: Sonia Vieira.

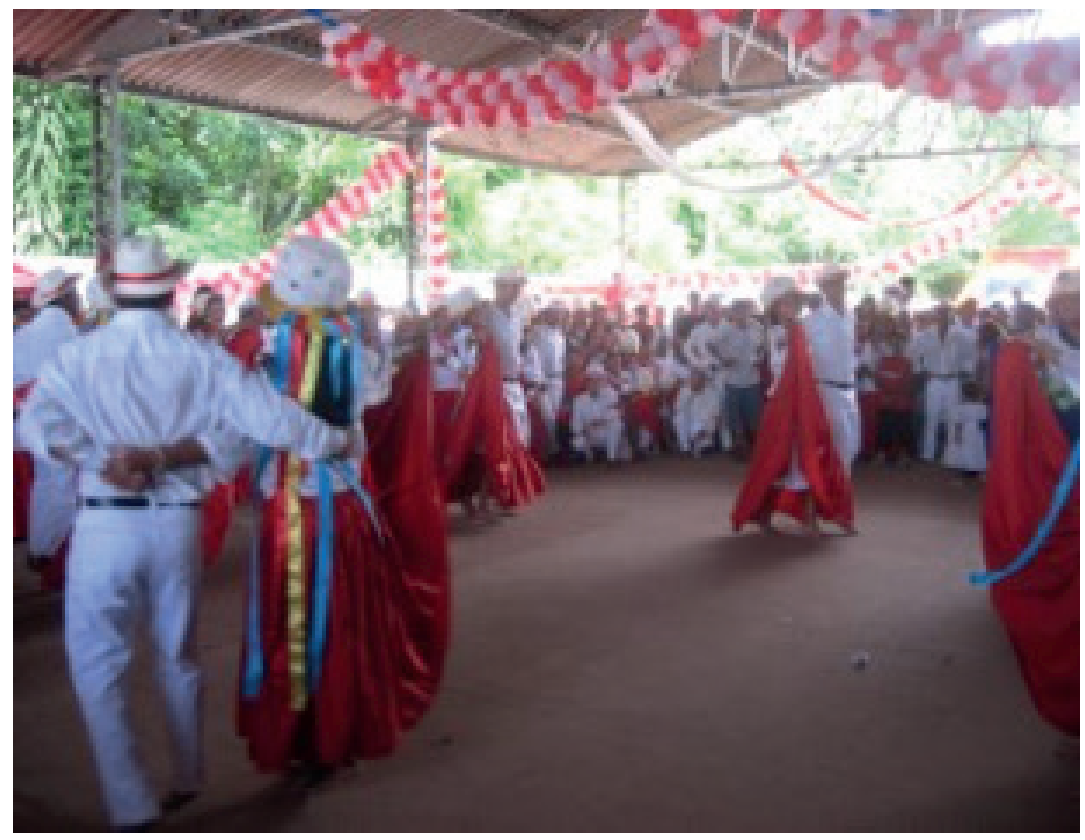

Desde os meus primeiros contatos adquiridos com o grupo migrante que festeja São Benedito, tenho ouvido relatos que remetem a uma relação forte, algo como uma pertença e, também adesão a seu lugar de origem. Esse

7 É perceptível ambiguidade do santo.

8 Há sinais de um conflito pela posse do santo entre Careca e dona Amélia .

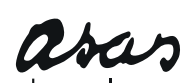

VOL. 16 | N.1 | JUN. 2019 da palavra ISSN 1415-7950 "sentir-se" bragantino, que Careca e o "pessoal lá de Bragança" - lembrado por mim, no seu sentido positivado - tanto manifestado, penso ser análogo ao sentimento de pertencimento de que trata Motta-Maués (1997) quando se refere aos afrobrasileiros:

Essa ideia da 'volta às raizes', o 'retorno' de que fala Y. Ferreira, ou a 'volta', como dizia Gil passa por uma sensação de ligação a essas raizes (nesse sentido, sentir-se africano), por sua vez ancorada num raciocínio encopassador, que junta em si todos os elementos da proposta inicial. Então, é possível voltar (à África), sentir-se (africano), 
aderir à negritude (oposta ao branqueamento), tudo isso porque, na verdade, nunca se deixou de sê-lo, de estar lá. Posto que, na raiz da interpretação, ou na definição da negritude pelos movimentos negros no Brasil, está a consideração da existência de uma especificidade negra dada pelos valores negro- africanos (uma alma negra) cuja matriz é a Africa (uma essência africana) que se carrega enquanto tal, onde for, sendo sempre possivel (para o MN,102 politicamente preciso) fazer vir á tona essa ligação original. (MOTTA-MAUES, 1997, p. 254-255).

A partir disso, a autora irá discutir a ideia dessa "volta às raízes", da negritude, ou seja, da "africanidade", que Motta-Maués (1997) define como referência a uma cultura negra, coisas partilhadas por todos os caminhantes da diáspora, dispersos, longe da mãe África. Ao dizer isso, a autora enfatiza que este fenômeno pode encontrar correspondência, por esdrúxulo que possa parecer, segundo ela, um contraponto, com o conceito de "germanidade" (Deutschtum), manifestado por alemães e descendentes de alemães, que imigraram no início do século para o sul do Brasil. (SEYFERTH, 1982) Assim, utilizo-me aqui, tanto da definição de Motta-Maués, como de Seyferth, vendo o caso dos migrantes bragantinos que manifestam em suas falas e na própria devoção a São Benedito de modo semelhante ao sentimento de pertencimento traduzido como "bragantinidade". Esse conceito é construído como o de africanidade/germanidade, pelas pessoas, a partir de seus contextos. Como evidência, frases que ouvi em campo: "É como se eu estivesse lá em Bragança" ou ainda "todos aqui formamos uma mesma família 103", e ainda,

um bragantino reconhece outro bragantino aonde quer que ele esteja". Entendo que se assemelha à questão da germanidade, onde a autora cita "um alemão permanece sempre alemão (...) em qualquer parte do mundo (...) um alemão permanece sempre alemão, ainda que seu berço se situe na América. (SEYFERTH, 198, p. 126).

Essa construção da "bragantinidade" está ancorada em um conjunto de elementos representativos, dentre estes a devoção a São Benedito e a dança da Marujada, dois elementos que se complementam na prática. Relação também traduzida como na frase do capítulo anterior á analogia da "farofa" significando a unidade entre os não-bragantinos, moradores de Ananindeua: de devotos (de São Benedito) e de Marujos (dançadores da Marujada) e que também é compartilhada pelos bragantinos de fora (os que não organizam a festa), mas que participam dela a cada ano. Com o perdão pela comparação, e pela grande diferença da presentificação de sua história, sua proximidade e possibilidade de retorno a Bragança durante a festa, são como se os bragantinos de Ananindeua, tal como os teutobrasileiros, para Seyferth e os afrobrasileiros, para Motta-Maués, precisassem "carregar" com eles a devoção e a dança como sua "alma" e suas "raízes" para viver e ser. Afirmo ainda, que a devoção á São Benedito através da festa é única, no sentido de sua realização e utilização por esses migrantes.

\section{CONCLUSÃO}

A fim de refazer uma outra festa, com uma estrutura pensada para outro contexto e passível de escolhas, críticas, preferências, permutas. Porém, a identidade de "bragantino" é o que será celebrado sempre; e nas demais festas em homenagem a São Benedito estiver acontecendo, se houver um bragantino presente; ele se utilizará do modelo de Bragança para emoldurar a devoção a São Benedito, ou simplesmente ao "Pretinho", este o "São Benedito de Ananindeua", como vimos eles dizem mesmo "ser bragantino é dançar Marujada e ser devoto de São Benedito" e poder gritar: "Viva o Glorioso!" 


\section{REFERÊNCIAS}

DURAND, Gilbert. Ciência do homem e tradição: o novo espírito antropológico/ Gilbert Durand: tradução de Lucia Pereira de Sousa. 1ª ed. São Paulo: Triom, 2008.

GALVÃO, Eduardo. Vida religiosa do caboclo da Amazônia. In: Boletim Nacional, Nova Série - Antropologia. Rio de Janeiro, 1953.

. Santos e Visagens: Um estudo da vida religiosa de Ita, Baixo Amazonas. $2^{\mathrm{a}}$ ed. Tese de doutorado. São Paulo: Brasiliana Nacional, 1955.

HOONAERT, Eduardo. A cristandade durante a primeira é poça colonial. In: HOORNAERT, Eduardo et al. História da igreja no Brasil: ensaio de interpretação a partir do povo. $3^{\text {a }}$ ed. São Paulo: Paulinas/Petrópolis: Vozes, 1983. Tomo II/I.

MOTTA MAUÉS, Maria Angelica. Negro sobre Negro: a questão racial no pensamento das elites negras brasileiras. Tese (Doutorado em Sociologia). IUPERG-Tec. Rio de Janeiro, 1997.

MAUÉS, Raymundo Heraldo. Padres, pajés, santos e festas: Catolicismo popular e controle eclesiástico. Belém: CEJUP, 1995.

Belém: Cejup, 1999.

Uma outra "invenção" da Amazônia: religiões, histórias e identidades.

NONA TODA SILVA, Dário Benedito. Os Donos de São Benedito, Convenções e rebeldias na luta entre o catolicismo tradicional e devocional na cultura de Bragança, século XX. Dissertação de Mestrado em História Social da Amazônia. Universidade Federal do Pará. Belém, 2006.

QUINTÃO, Antonia Aparecida. Lá vem meu parente: As irmandades de preto se pardos no Rio de Janeiro e em Pernambuco. (Século XVIII). $1^{\mathrm{a}}$ ed. São Paulo: ANNABLUME, 2002.

SOARES, Mariza de Carvalho. Devotos da cor. Rio de Janeiro: Civilização Brasileira, 2000 .

SILVA, Dedival Brandão da. Os tambores da esperança: um estudo sobre a cultura, religião, simbolismo e ritual na festa de São Benedito da cidade de Bragança. Bragança: Falangola, 1997.

SCARANO, Julita. Devoção e Escravidão. A Irmandade de Nossa Senhora do Rosario dos Pretos no Distrito Dia mantino no Século XVIII, $2^{\mathrm{a}}$ ed. C $^{\mathrm{a}}$ Editoral Nacional, 2014.

VAUCHEZ, André. A espiritualidade na Idade Média: Séculos VIII a XIII. Rio de Janeiro: Jorge Zahar, 1995.

VIEIRA, Sônia Cristina de Albuquerque. “É um pessoal lá de Bragança...”: Um estudo antropológico acerca de identidades e numa festa de migrantes para São Benedito em Ananindeua /PA. Dissertação (Mestrado em Antropologia) Programa de Pós-Graduação em Ciências Sociais, Universidade Federal do Pará. Belém, 2008.

Recebido em 20 Mai $2019 \quad$ Aprovado em 21 Jun 2019

Sonia Cristina de Albuquerque VIEIRA

Doutora em Ciências Sociais - Antropologia pela UFPA. Possui graduação em Licenciatura Plena em Ciências da Religião pela Universidade do Estado do Pará (2005). E-mail: soniacristinav@hotmail.com 